\title{
Kinetic Models of the Prebiotic Replication of dsRNA under Thermal Cycling Conditions
}

\author{
Pauline M. Schwartz ${ }^{1}$, Dante M. Lepore ${ }^{1} \&$ Carl Barratt ${ }^{2}$ \\ ${ }^{1}$ Department of Chemistry and Chemical Engineering, Tagliatela College of Engineering, University of New \\ Haven, USA \\ ${ }^{2}$ Department of Mechanical, Civil and Environmental Engineering, Tagliatela College of Engineering, University \\ of New Haven, USA \\ Correspondence: Pauline Schwartz, Department of Chemistry and Chemical Engineering, Tagliatela College of \\ Engineering, University of New Haven, West Haven, CT 06516, USA. Tel: 203-932-7170, Fax: 203-931-6077. \\ E-mail: pschwartz@newhaven.edu
}

Received: August 8, 2012 Accepted: August 23, 2012 Online Published: September 14, 2012

doi:10.5539/ijc.v4n5p9 URL: http://dx.doi.org/10.5539/ijc.v4n5p9

\begin{abstract}
We present computational models for the replication of double stranded RNA (dsRNA) or related macromolecules under thermal cycling conditions that would reflect prebiotic (i.e. non-enzymatic) environments. Two models of the replication of dsRNA are represented as multi-step chemical systems. The objective of this investigation was to better understand the kinetic features of such chemical systems. It is shown that thermal cycling in a chemical system is advantageous (relative to a fixed temperature) if there are two competing reactions, one favored at high temperature and one favored at low temperature. For the prebiotic replication of dsRNA, a high temperature favors formation of the two single stranded RNA (ssRNA) templates and a presumptive catalysis or catalytic surface is active at low temperature at which the ssRNA template is copied. Our models may facilitate understanding possible prebiotic conditions for the replication of dsRNA.
\end{abstract}

Keywords: RNA World, temperature cycles, systems chemistry, prebiotic chemistry

\section{Introduction}

We have investigated computational models of hypothetical chemical systems that, under appropriate conditions, demonstrate thermal cycling to be unexpectedly productive (Osipovitch, Barratt, \& Schwartz, 2009). In experimental systems, thermal cycling has not been well explored; the vast majority of chemical reactions are carried out under fixed, constant conditions. In contrast, a biochemical system well studied under thermal cycling conditions is the polymerase chain reaction. To validate our original theoretical models, we extended them to simulate two-temperature PCR, which is a modification of more common three-temperature PCR (Barratt et al., 2010). Two-temperature PCR is a laboratory procedure for replicating dsDNA in a cyclic manner facilitated by a heat stable polymerase. In brief, at a high temperature, dsDNA denatures to two single strands of DNA and, at the lower temperature, primers anneal and deoxyribonucleotide triphosphates extend a complementary DNA chain catalyzed by DNA polymerase. After 20-40 cycles, a small number of dsDNA molecules are highly amplified. We found that our chemical model system reproduced the critical features of the replication of dsDNA using a two-temperature protocol (Barratt et al., 2010).

Having shown that our chemical model system was predictive of an established experimental system, we planned to extend our computational model to explore the fascinating suggestion that thermal cycling might have played a key role in the synthesis of double stranded RNA (dsRNA) or dsRNA-like molecules under prebiotic, non-enzymatic, conditions on the early Earth. Understanding prebiotic conditions for synthesis of RNA would be very valuable in supporting the concept of an RNA World (Orgel, 2004; Ferris \& Delano, 2008; Robertson \& Joyce, 2010). Conditions for replicating RNA under prebiotic conditions are far from clear. It is not known if catalytic surfaces could utilize ribonucleotides or some chemically activated ribonucleotides to replicate large polymers of RNA. Another mechanism might have ligated smaller oligonucleotides to form dsRNA. In either of these cases, demonstrating non-enzymatic routes to the replication of dsRNA or related macromolecules is necessary to understand the synthesis of sufficient copies of this molecule to express molecular function, such as the catalytic activity of ribozymes. The copying mechanism would inevitably generate mutations that would lead 
to selection of advantageous sequences (Müller, 2006; Cheng \& Unrau, 2010; Benner, Kim, \& Yang, 2010). Thus, a replicating mechanism for RNA would be important for providing the macromolecules needed to initiate life. The models proposed in this paper describe poorly investigated routes to the replication of prebiotic RNA via thermal cycling and may facilitate the design of experimental systems.

\section{Computational Models and Results}

We have designed two systems for the replication of dsRNA under thermal cycling conditions. In Model I, we hypothesize a catalytic surface on which single stranded RNA (ssRNA) acts as a template for the polymerization of monomers to give dsRNA. In Model II, small oligomers ligate on an ssRNA template.

The proposed models were explored computationally using a powerful chemical kinetics program, Kintecus 4.01 (Ianni, 2010). Kintecus is based on deterministic methods that use the Arrhenius equation to describe the overall kinetics of a chemical system and that solve the ordinary differential equations governing the chemical reactions; Kintecus uses a well described Runge-Kutta based integrator (Ianni, 2003). As a deterministic program, the inputs include: the reaction steps, energies of activation $\left(E_{a}\right)$, the Arrhenius constant, $A$, and the temperature or temperature cycle. Arrhenius parameters together with suitable initial conditions and a temperature range of $300 \mathrm{~K}$ to $370 \mathrm{~K}$ were chosen to accentuate features of the chemical systems for replication of dsRNA or related macromolecules under thermal cycling. The program assumes elementary reaction steps and numerically solves the governing differential equations for the system. The concentrations of dsRNA or other participating species are calculated and displayed over time. Results from Kintecus were confirmed analytically; such analysis was described explicitly in our earlier paper (Barratt et al., 2010).

\subsection{Model I-RNA Replication from Monomers}

Model I is the prebiotic replication of RNA via the complementary dsRNA and is based on our prior investigation of models for the two-temperature polymerase chain reaction to synthesize DNA (Barratt et al., 2010). The two-temperature system for replicating RNA assumes a catalytic surface (i.e. non-enzymatic) that is temperature sensitive and a low but non-limiting concentration of the substrates. The chemical system for Model I is:

$$
\begin{aligned}
& \text { ssRNA } 1+\text { SUB }+ \text { CAT(act) } \rightarrow \text { dsRNA + CAT(act) } \\
& \text { ssRNA2 + SUB + CAT(act) } \rightarrow \text { dsRNA + CAT(act) } \\
& \text { dsRNA } \rightleftharpoons \text { ssRNA } 1+\text { ssRNA2 } \\
& \text { CAT(act) } \rightarrow \text { CAT(inact) } \\
& \text { CAT(inact) } \rightarrow \text { CAT(act) }
\end{aligned}
$$

In Model I, CAT represents a temperature sensitive catalytic surface, SUB represents the substrates (nucleotide precursors), and ssRNA1 and ssRNA2 are complementary RNA sequences.

We found reaction conditions and kinetic parameters for Model I such that at high temperatures, reaction 3 would yield ssRNA template molecules. At high temperatures, the equilibrium of reactions 5 and 6 shifts to an

\begin{tabular}{|c|c|c|c|c|c|c|}
\hline \# & Reaction & A & $\mathrm{Ea}$ & $\mathrm{k}$ at $300 \mathrm{~K}$ & $\mathrm{k}$ at $370 \mathrm{~K}$ & $\begin{array}{l}(\mathrm{k} \text { at } 370 \mathrm{~K}) /(\mathrm{k} \text { at } \\
300 \mathrm{~K})\end{array}$ \\
\hline 1 & $\begin{array}{l}\text { ssRNA1 + SUB + CAT }(\text { act })==>\text { dsRNA } \\
+ \text { CAT(act) }\end{array}$ & $1.00 \mathrm{E}+01$ & 10 & $1.82 \mathrm{E}-01$ & $3.88 \mathrm{E}-01$ & $2.14 \mathrm{E}+00$ \\
\hline 2 & $\begin{array}{l}\text { ssRNA2 }+ \text { SUB }+ \text { CAT }(\text { act })=\Rightarrow \text { dsRNA } \\
+ \text { CAT(act) }\end{array}$ & $1.00 \mathrm{E}+01$ & 10 & $1.82 \mathrm{E}-01$ & $3.88 \mathrm{E}-01$ & $2.14 \mathrm{E}+00$ \\
\hline 3 & $\mathrm{dsRNA}==>$ ssRNA1 + ssRNA2 & $2.00 \mathrm{E}+16$ & 125 & $3.44 \mathrm{E}-06$ & 4.51E-02 & $1.31 \mathrm{E}+04$ \\
\hline 4 & ssRNA1 + ssRNA2 $=>$ dsRNA & $1.00 \mathrm{E}+00$ & 10 & $1.82 \mathrm{E}-02$ & $3.88 \mathrm{E}-02$ & $2.14 \mathrm{E}+00$ \\
\hline 5 & CAT(inact) $==>$ CAT(act) & $1.00 \mathrm{E}+00$ & 5 & $1.35 \mathrm{E}-01$ & $1.97 \mathrm{E}-01$ & $1.46 \mathrm{E}+00$ \\
\hline 6 & CAT(act) $==>$ CAT(inact) & $1.00 \mathrm{E}+16$ & 90 & $2.14 \mathrm{E}+00$ & $1.97 \mathrm{E}+03$ & $9.22 \mathrm{E}+02$ \\
\hline
\end{tabular}
inactive catalyst or catalytic surface $\left(\mathrm{CAT}_{\text {inact }}\right)$. At low temperatures, the equilibrium shifts to the active $\mathrm{CAT}_{\text {act }}$ and drives reactions 1 and 2 to synthesize more dsRNA with a low but constant concentration of available substrates (SUB). The kinetic description of Model I is shown in Table 1.

Table 1. Kinetic descriptions of Model I 
$\mathrm{A}$ is the pre-exponential factor and $\mathrm{Ea}$ is the energy of activation for the Arrhenius equation, rate constant $(\mathrm{k})=\mathrm{A}$ $\mathrm{e}^{-(\mathrm{Ea} / \mathrm{RT})}$; the units for $\mathrm{Ea}$ are $\mathrm{kJ} / \mathrm{mol}$ and the units for $\mathrm{A}$ and $\mathrm{k}$ depend on the order of the reaction. dsRNA and ssRNA are double-stranded and single stranded RNA's; ssRNA1 is complementary to ssRNA2. SUB is the pool of nucleotide substrates for RNA. CAT is the temperature dependent catalyst or catalytic surface; CAT $_{\text {act }}$ is active and $\mathrm{CAT}_{\text {inact }}$ is inactive.

In addition to the kinetic parameters noted in Table 1, reaction conditions included the initial concentration of dsRNA as $1 \times 10^{-5} \mathrm{M}$, the concentration of the general pool of substrates (SUB) as a constant $1.0 \times 10^{-3} \mathrm{M}$ and the presence of the catalyst CAT(act) as $1.0 \mathrm{M}$. The temperature cycle was chosen as $10 \%$ at $370 \mathrm{~K}$ and $90 \%$ at $300 \mathrm{~K}$ for 20 cycles. We chose kinetic parameters and reaction conditions to investigate whether the chemical system could support replication of RNA through dsRNA with temperature cycling.

With the constraints shown, we found that Model I predicted the concentration of dsRNA under thermal cycling conditions as shown in Figure 1. We have found that more dsRNA is synthesized under thermal cycling than at any constant temperature between $300 \mathrm{~K}$ and $370 \mathrm{~K}$; analysis of Model $\mathrm{I}$ is similar to that reported for the two-temperature PCR for DNA (Barratt et al., 2010).

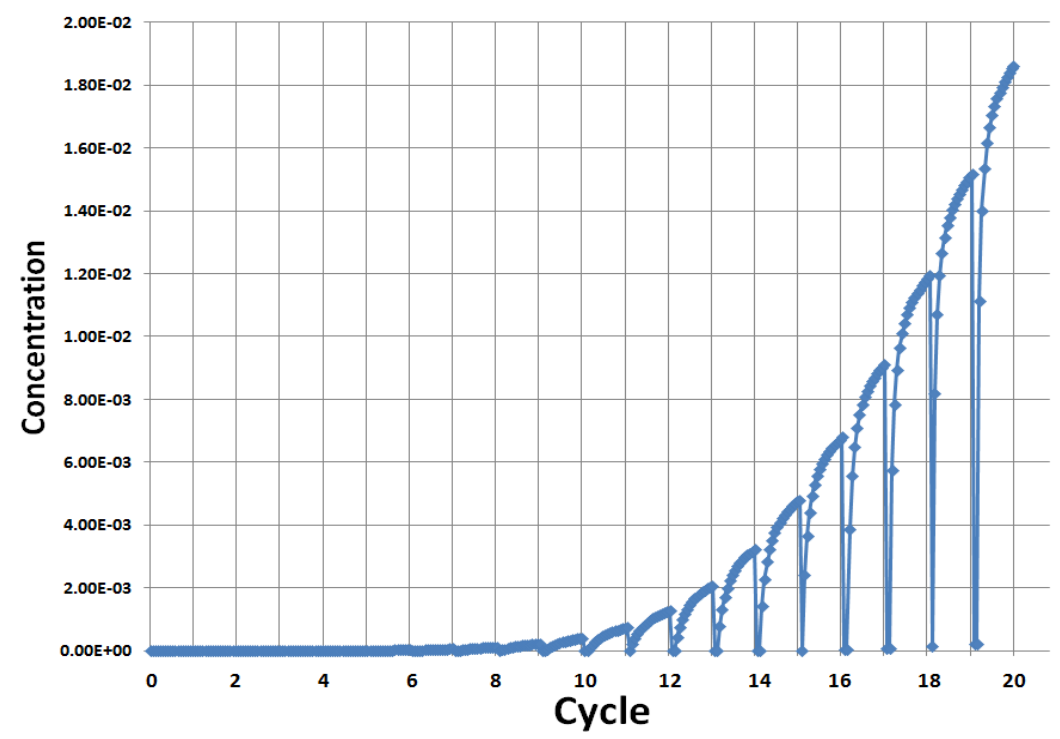

Figure 1. Concentration of dsRNA predicted by Model I as described in Table 1

The initial concentration of dsRNA is $1 \times 10^{-5} \mathrm{M}$, SUB (substrates) is $1.0 \times 10^{-3} \mathrm{M}$ (constant) and CAT(act) is $1.0 \mathrm{M}$. Temperature cycle: $10 \%$ at $370 \mathrm{~K}$ and $90 \%$ at $300 \mathrm{~K}$ for 20 cycles.

\subsection{Model II-RNA Replication by Ligation Using Oligomers}

Initially, we explored a simple chemical system for replication of dsRNA using oligonucleotides.

$$
\begin{gathered}
\text { dsRNA } \rightleftharpoons \text { ssRNA } 1+\text { ssRNA2 } \\
\text { OLIGO1A }+ \text { OLIGO1B + ssRNA2 } \rightarrow \text { dsRNA } \\
\text { OLIGO2A + OLIGO2B + ssRNA } \rightarrow \text { dsRNA }
\end{gathered}
$$

Where OLIGO's are small oligonucleotides; OLIGO1A and OLIGO1B ligate to form ssRNA1 using ssRNA2 as a template and OLIGO2A and OLIGO2B ligate to form ssRNA2 using ssRNA1 as a template. ssRNA1 and sSRNA2 are complementary and form dsRNA. In this system we were unable to find kinetic parameters for which thermal cycling was significantly better than constant temperature. For example, in one case with 20 cycles $(10 \%$ at $370 \mathrm{~K}$ and $90 \%$ at $300 \mathrm{~K})$ a starting concentration of $1.0 \times 10^{-5} \mathrm{M}$ dsRNA increased to $1.56 \times 10^{-2} \mathrm{M}$ dsRNA but the replication of dsRNA at a fixed temperature of $316 \mathrm{~K}$ gave $75 \%$ of the amount of dsRNA under thermal cycling. It proved necessary to modify our simple system to include a catalytic component.

Model II simulates replication of RNA by ligation of oligomers and is based on systems described by Lincoln and Joyce (Lincoln \& Joyce, 2009) - which were investigated at a fixed temperature - and later extended by others (Kim et al., 2008). As noted above, we found that the chemical system that replicated RNA under thermal cycling conditions required a catalytic surface. The chemical system is: 


$$
\begin{gathered}
\text { dsRNA } \rightleftharpoons \text { ssRNA1 + ssRNA2 } \\
\text { ssRNA1 }+ \text { CAT }(\text { act }) \rightarrow \text { ssRNA1CAT } \\
\text { ssRNA2 }+ \text { CAT }(\text { act }) \rightarrow \text { ssRNA2CAT } \\
\text { OLIGO2A }+ \text { OLIGO2B }+ \text { ssRNA1CAT } \rightarrow \text { dsRNA }+ \text { CAT(act) } \\
\text { OLIGO1A }+ \text { OLIGO1B }+ \text { ssRNA2CAT } \rightarrow \text { dsRNA }+ \text { CAT(act) } \\
\text { CAT (act) } \rightarrow \text { CAT(inact) } \\
\text { CAT(inact) } \rightarrow \text { CAT(act) }
\end{gathered}
$$

We found kinetic parameters for the ligation of oligomers to generate dsRNA such that one reaction at elevated temperatures favored formation of the ssRNAs but lower temperatures favored $\mathrm{CAT}_{\text {act }}$. A kinetic description of Model II is shown in Table 2.

In addition to the kinetic parameters noted in Table 2, reaction conditions included the initial concentration of dsRNA as $1 \times 10^{-6} \mathrm{M}$, the concentration of the general pool of oligomers (OLIGO) as a $1.0 \mathrm{M}$ excess and the presence of the catalyst CAT(act) as $1.0 \mathrm{M}$. The temperature cycle was chosen as $10 \%$ at $370 \mathrm{~K}$ and $90 \%$ at $300 \mathrm{~K}$ for 20 cycles. We chose kinetic parameters and reaction conditions to investigate whether the chemical system could support replication of RNA through oligomer ligation with temperature cycling.

The concentration of dsRNA predicted by Model II under thermal cycling conditions is shown in Figure 2. It is found that little or no dsRNA replication occurs under constant temperature conditions; the maximal replication of dsRNA at a fixed temperature occurred at $310 \mathrm{~K}$ and produced less than $8 \%$ of that made with thermal cycling.

Table 2. Kinetic descriptions of Model II

\begin{tabular}{ccccccc}
\hline & Reaction & $\mathrm{A}$ & $\mathrm{Ea}$ & $\mathrm{k}$ at $300 \mathrm{~K}$ & $\mathrm{k}$ at $370 \mathrm{~K}$ & $\begin{array}{c}(\mathrm{k} \text { at 370K }) / \\
(\mathrm{k} \text { at 300K) }\end{array}$ \\
\hline 1 & dsRNA ==> RNA1 + RNA2 & $2.00 \mathrm{E}+16$ & 125 & $3.44 \mathrm{E}-06$ & $4.51 \mathrm{E}-02$ & $1.31 \mathrm{E}+04$ \\
2 & RNA1 + RNA2 ==> dsRNA & $1.00 \mathrm{E}+00$ & 10 & $1.82 \mathrm{E}-02$ & $3.88 \mathrm{E}-02$ & $2.14 \mathrm{E}+00$ \\
3 & RNA1 + CAT(act) ==> RNA1CAT & $1.00 \mathrm{E}+00$ & 20 & $3.29 \mathrm{E}-04$ & $1.50 \mathrm{E}-03$ & $4.56 \mathrm{E}+00$ \\
4 & RNA2 + CAT(act) ==> RNA2CAT & $1.00 \mathrm{E}+00$ & 20 & $3.29 \mathrm{E}-04$ & $1.50 \mathrm{E}-03$ & $4.56 \mathrm{E}+00$ \\
& OLIGO1A + OLIGO1B + & & & & & \\
5 & RNA2CAT = dsRNA + CAT(act) & $1.00 \mathrm{E}+01$ & 20 & $3.29 \mathrm{E}-03$ & $1.50 \mathrm{E}-02$ & $4.56 \mathrm{E}+00$ \\
& OLIGO2A + OLIGO2B + & & & & & \\
6 & RNA1CAT ==> dsRNA + CAT(act) & $1.00 \mathrm{E}+01$ & 20 & $3.29 \mathrm{E}-03$ & $1.50 \mathrm{E}-02$ & $4.56 \mathrm{E}+00$ \\
7 & CAT(inact) $==>$ CAT(act) & $1.00 \mathrm{E}+00$ & 5 & $1.35 \mathrm{E}-01$ & $1.97 \mathrm{E}-01$ & $1.46 \mathrm{E}+00$ \\
8 & CAT(act) $==>$ CAT(inact) & $1.00 \mathrm{E}+16$ & 90 & $2.14 \mathrm{E}+00$ & $1.97 \mathrm{E}+03$ & $9.22 \mathrm{E}+02$ \\
\hline
\end{tabular}

$\mathrm{A}$ is the pre-exponential factor and $\mathrm{E}_{\mathrm{a}}$ is the energy of activation for the Arrhenius equation, rate constant $(\mathrm{k})=\mathrm{A}$ $\mathrm{e}^{-(\mathrm{E} / \mathrm{RT})}$; the units for $\mathrm{E}_{\mathrm{a}}$ are $\mathrm{kJ} / \mathrm{mol}$ and the units for $\mathrm{A}$ and $\mathrm{k}$ depend on the order of the reaction. OLIGO's are small oligonucleotides; OLIGO1A and OLIGO1B ligate to form ssRNA1 using ssRNA2 as a template and OLIGO2A and OLIGO2B ligate to form ssRNA2 using ssRNA1 as a template. ssRNA1 and ssRNA2 are complementary and form dsRNA. CAT is the temperature dependent catalyst or catalytic surface; $\mathrm{CAT}_{\text {act }}$ is active and $\mathrm{CAT}_{\text {inact }}$ is inactive. 


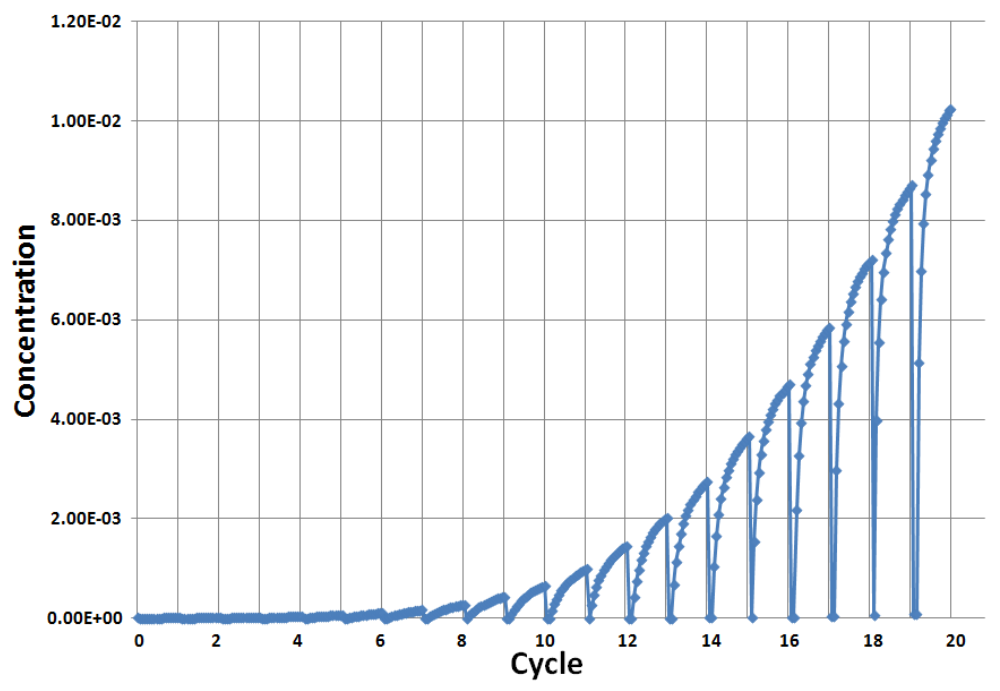

Figure 2. Concentration of dsRNA predicted by Model II as described in Table 2

The initial concentrations of dsRNA is $1 \times 10^{-6} \mathrm{M}$, each OLIGO is $1.0 \mathrm{M}$ (excess) and CAT is $1.0 \mathrm{M}$. The temperature cycle $10 \%$ at $370 \mathrm{~K}$ and $90 \%$ at $300 \mathrm{~K}$ for 20 cycles.

\section{Discussion and Conclusions}

A more complete understanding of prebiotic chemistry has been the recent goal of important agencies, the European Cooperation on Science and Technology, (Von Kiedrowski, 2007) and NASA's Astrobiology Institute (Des Marais et al., 2008). Systems chemistry has been a useful approach to uncovering clues about the chemical evolution of life on Earth and elsewhere. Efforts in systems chemistry have been useful in appreciating the interaction of chemical reactions, especially the important perspective that even simple systems can behave in a non-linear fashion.

We have examined the kinetics of chemical systems designed to replicate dsRNA to understand the potential role of thermal cycling conditions within an RNA World scenario. Although it remains controversial if RNA or related macromolecules were "first," RNA synthesis would certainly have been a key bridge from abiotic chemistry to the biotic world (Orgel, 2004; Taylor, 2005; Müller, 2006; Ferris \& Delano, 2008; Robertson \& Joyce, 2010; Cheng \& Unrau, 2010; Benner, Kim, \& Yang, 2010). Models of RNA replication play an important role in inspiring experiments that would provide evidence for the RNA World. Less directly, the models may provide insights into the chemical evolution of certain RNA viruses (Holmes, 2011).

In light of little direct experimental support, our kinetic models at least suggest a basis for thermal cycling as a potential condition for prebiotic synthesis of dsRNA. For Model I, there is evidence that RNA synthesis is facilitated on catalytic surfaces such as montmorillonite clays or other crystal surfaces (Vlassov et al., 2005; Ferris \& Delano, 2008, Joshi et al., 2009). De Roos postulated a PCR-like mechanism (De Roos, 2007). Model II is based on the studies of Lincoln and Joyce showing that dsRNA synthesis can occur via an RNA template acting as a ribozyme ligating small RNA oligomers (Lincoln \& Joyce, 2009). Kim et al. extended this system showing that alternating temperature cycles did increase the rate of RNA synthesis (Kim et al., 2008).

Analysis of the kinetics is made difficult by the non-linear dynamics that are the signature of the models but there is a critical inverse relationship in steps leading to important intermediates such that one is highly favored at the high temperature and the other is highly favored at the low temperature. In Model I, for example, melting of dsRNA to provide the RNA single-stranded templates predominates only at the high temperature; it should be noted that even a 40 -mer GC polymer has a melting temperature close to $370 \mathrm{~K}$. Only at the low temperature, however, is there significant availability of the active catalytic surface. At neither the high nor low temperature alone is there significant synthesis of the dsRNA. Our models indicate that kinetic parameters can be found to promote replication of dsRNA with thermal cycling; unlike PCR where it is essential to have laboratory conditions that are efficient, i.e. period doubling, the objective of our models was to find conditions that permitted replication of dsRNA under thermal cycling conditions. In addition to arbitrary kinetic parameters, other possible variables include the temperature range, thermal cycling profile, and initial concentrations of reacting species.

As with any hypothetical chemical system, we move from a "molecular biologists' dream" to the "prebiotic 
chemists' nightmare," which constrains all models to the reality of chemistry (Orgel, 2004; Taylor, 2005; Benner, Kim, \& Yang, 2010). Our models make assumptions and simplifications in order to examine the critical features of dsRNA replication under thermal cycling conditions. Important chemical considerations for synthesis of dsRNA in prebiotic environments include:

- identification, synthesis and availability of the monomer units

- the nature of the polymerization reaction and competing degradation reactions

- the catalytic activity or surface needed to support replication or ligation

- thermodynamic and kinetic considerations for the free energy driving the reactions

- reaction conditions including temperature, $\mathrm{pH}$ and the presence of ancillary small molecules

- time course for evolving a pool of critical dsRNAs

- stability of RNA (or RNA-like) polymers at elevated temperatures

We have developed two computational models that describe the kinetic basis for synthesis of dsRNA under thermal cycling conditions. Cycling conditions, including temperature cycles, may be caused by such conditions as convection currents in an ocean environment, climate changes, wet and dry cycles or light and dark cycles; such cycling conditions might result in changes in concentrations of critical molecules (Muller, 2005). Even small temperature ranges for thermal cycling may be of interest, such as those that occur between ice crystal surfaces and liquid water (Trinks, Schröder, \& Biebricher, 2005; Monnard \& Szostak, 2008). It is assumed that cycling conditions support interacting reactions that would not occur with fixed temperature conditions. Furthermore, the kinetics of the chemical system are likely to be non-linear and thus difficult to predict. Where, as yet, there is little experimental support for cycling conditions, our models suggest the feasibility for thermal cycling to have played a key role in prebiotic replication of RNA. Thus we hope our models can be used as the basis for more complete investigations.

\section{Acknowledgments}

CB and PMS gratefully acknowledge funding through the Connecticut Space Grant Consortium and the University of New Haven Faculty Research Support. DML thanks the University for supporting undergraduate summer fellowships and NASA for a CT Space Grant Fellowship.

\section{References}

Barratt, C., Lepore, D. M. Cherubini, M. J., \& Schwartz, P. M. (2010). Computational models of thermal cycling in chemical systems. International Journal of Chemistry, 2(2), 19-27.

Benner, S. A., Kim, H-J, \& Yang, Z. (2010). Setting the stage: The history, chemistry, and geobiology behind RNA. Cold Spring Harb Persect Biol. http://dx.doi.org/10.1101/cshpersect.a003541

Cheng, L. K. L., \& Unrau, P. J. (2010). Closing the circle: Replicating RNA with RNA. Cold Spring Harb Perspect Biol. http://dx.doi.org/10.1101/cshperspect.a002204

De Roos, D. G. (2007). Modeling evolution on design-by-contract predicts an origin of life through an abiotic double-stranded RNA world. Biology Direct, 2, 12. http://dx.doi.org/10.1186/1745-6150-2-12

Des Marais, D. J., Nuth, J. A., Allamandola, L. J., Boss, A. P., Farmer, J. D., Hoehler, T. M., ... Spormann, A. M. $\begin{array}{llll}\text { (2008). The NASA Astrobiology Roadmap. Astrobiology, 8, } & \text { 715-730. }\end{array}$ http://dx.doi.org/10.1089/ast.2008.0819

Ferris, J. P., \& Delano, J. W. (2008). The RNA world scenario for the origin of life. In Chemical Evolution across Space and Time: From the Big Bang to Prebiotic Chemistry, ACS Symposium Series edited by. Zaikowski \& Friedrich, Oxford University Press, 293-308. http://dx.doi.org/10.1021/bk-2008-0981.ch016

Holmes, E. C. (2011). What does virus evolution tell us about virus origins? J. Virology, 85, 5241-5247. http://dx.doi.org/10.1128/JVI.02203-10

Ianni, J. C. (2010). Kintecus, Windows Version 4.01(2010). Retrieved from: http://www.kintecus.com and Kintecus Manual, retrieved from: http://www.kintecus.com/Kintecus_V400.pdf

Ianni, J. C. (2003). A comparison of the Bader-Deuflhard and Cash-Karp Runge-Kutta integrators for the GRIMECH 3.0 model based on the chemical kinetics code Kintecus. In: Bathe, K.J. (Ed.), Computational Fluid and Solid Mechanics. Amsterdam: Elsevier, 1368-1372. http://dx.doi.org/10.1016/B978-008044046-0.50335-3 
Joshi, P. C., Aldersley, M. F., Delano, J. W., \& Ferris, J. P. (2009). Mechanism of montmorillonite catalysis in the formation of RNA oligomers. J. Am. Chem. Soc., 131, 13369-13374. http://dx.doi.org/10.1021/ja9036516

Kim, K. S., Oh, S., Yea, S. S., Yoon, M. Y., \& Kim, D. E. (2008). Amplification of an RNA ligase ribozyme under alternating temperature conditions. FEBS Lett., 582(18), 2745-2752.

Lincoln, T. A., \& Joyce, G. F. (2009). Self-sustained replication of an RNA enzyme. Science, 323, 1229-1232. http://dx.doi.org/10.1126/science.1167856

Monnard, P. A., \& Szostak, J. W. (2008). Metal-ion catalyzed polymerization in the eutectic phase in water-ice: A possible approach to template-directed RNA polymerization. J. Inorg. Biochem., 102, 1104-1111. http://dx.doi.org/10.1016/j.jinorgbio.2008.01.026

Muller, A. W. J. (2005). Thermosynthesis as energy source for the RNA world: A model for the bioenergetics of the origin of life. Biosystems, 82(1), 93-102. http://dx.doi.org/10.1016/j.biosystems.2005.06.003

Müller, U. F. (2006). Re-creating an RNA world. Cell Mol Life Sci., 63(11), 1278-93. http://dx.doi.org/10.1007/s00018-006-6047-1

Orgel, L. E. (2004). Prebiotic chemistry and the origin of the RNA world. Critical Reviews in Biochemistry and Molecular Biology, 39, 99-123.

Osipovitch, D. C. Barratt, C., \& Schwartz, P. M. (2009). Systems chemistry and Parrondo's paradox: Computational models of thermal cycling. New Journal of Chemistry, 33, 2022-2027. http://dx.doi.org/10.1039/b900288j

Robertson, M. P., \& Joyce, G. F. (2010). The origins of the RNA world. Cold Spring Harb Perspect Biol. http://dx.doi.org/10.1101/cshperspect.a003608

Taylor, W. R. (2005). Modelling molecular stability in the RNA world. Computational Biology and Chemistry, 29, 259-272. http://dx.doi.org/10.1016/j.compbiolchem.2005.04.009

Trinks, H., Schröder W., \& Biebricher, C. F. (2005). Ice and the origin of life. Origins of Life and Evolution of the Biospheres, 35, 429-445. http://dx.doi.org/10.1007/s11084-005-5009-1

Vlassov, A. V., Kazakov, S. A., Johnston, B. H., \& Landweber, L. F. (2005). The RNA world on ice: A new scenario for the emergence of RNA information. J. Mol. Evol. 61, 264-273. http://dx.doi.org/10.1007/s00239-004-0362-7

Von Kiedrowski, G. (2007). Prebiotic Chemistry and Early Evolution-CMST COST Action D27: Final Report. Retrieved from: http://w3.cost.eu/fileadmin/domain_files/CMST/Action_D27/final_report/final_report-D27. pdf 